\section{Fouling mechanisms of submerged ultrafiltration membranes in greywater recycling}

${ }^{a, b}$ Nadine Oschmann, ${ }^{a}$ Long D. Nghiem, ${ }^{a^{*}}$ Andrea I. Schäfer

a Environmental Engineering, University of Wollongong, NSW, 2522, Australia. Tel: +61 2 4221 3385, Fax +61 24221 4738, E-mail: schaefer@uow.edu.au

${ }^{\mathrm{b}}$ University of Applied Science, TFH Berlin, 13353 Berlin, Germany Corresponding autho

\section{Abstract}

This study examined the influence of greywater constituents on the fouling behaviour of submerged hollow fibre UF membranes during greywater treatment for recycling purposes. Experiments were carried out on a bench-scale equipment using a Zenon ZW1 module. The membrane was operated under constant flux where an increase in transmembrane pressure was used to determine the extent of fouling. Wastewater constituent variables used in this study were kaolin, cellulose, humic acid, surfactant, and calcium concentration. Results indicate that during filtration of synthetic greywater multivalent ions like calcium played an important role. Depending on concentration agglomerates multivalent ions like calcium played an important role. Depending on concentration agglomerates
of different structure and size were formed and the structure and size determined the extent of of different structure and size were formed and the structure and size determined the extent of
fouling and retention. It was also shown that the surfactant sodium dodecyl sulphate (SDS) may fouling and retention. It was also shown that the surfactant sodium dodecyl sulphate (SDS) may
cause fouling through particle stabilisation and strongly interacts with calcium enhancing calcium cause fouling through particle stabilisation and strongly interacts with calcium enhancing calcium
retention especially in the critical micelle concentration $(\mathrm{cmc})$ region. It is hypothesized that SDS competes with humic acids (HAs) for adsorption sites resulting in lower $\mathrm{UV}_{254 \mathrm{~mm}}$ retention. Solution chemistry and cake deposition also influence the retention and hence product water quality.

Keywords: Ultrafiltration, greywater, fouling, calcium, surfactant

\section{Introduction}

. Declining water resources and deterioration of water quality are of growing concern, especially in arid or semiarid areas [1]. Fundamental changes are needed to improve the current wastewater management practice to ensure an efficient usage of our valuable water resources and the leas impact on the environment. In consequence, water recycling is increasing rapidly and applications of recycled wastewater range from large-scale industrial applications to small-scale systems for individual households. Greywater recycling could be an option to provide non-potable water to households and reduce the water usage per person to up to $50 \%$, which would bring environmental relief for both the water and the wastewater sector [2]

The characteristics and composition of greywater vary significantly depending on collection points and the behaviour of the household's inhabitants. Such variation may present a major difficulty for treatment applications and this is an essential consideration when evaluating the possibilities for treatment and reuse [3]. This study aims to provide a better understanding of the fouling and (to a limited extent) removal mechanisms.

\section{Background}

\subsection{Greywater}

Greywater is wastewater form bathtubs, showers, hand basins, laundry, washing machines, kitchen sinks and dishwashers excluding any input from the toilet. Greywater is deficient in trace element content and does not have the optimum nutrient ratio favourable for biological treatment [4]. Although, there is evidence that greywater can turn septic after extended periods of time, it may be more feasible to treat greywater purely by ultrafiltration (UF), since many pollutants can be effectively removed. Greywater accounts for about 65 to $75 \%$ of the water used in a household by volume [5]. While grey water contains much less pathogens, its physical and chemical characteristics are similar to that of domestic wastewater, which makes it much more suitable for non-potable reuse [5]. Non potable reuse applications of greywater in a household context can be toilet flushing, garden watering, laundry, or car washing.

The most important contaminants in greywater are organic and inorganic particulate matter dissolved organic matter, monovalent and multivalent salts, refractory organics like surfactants, and to a limited extent pathog no [5.67. After conding an in depth literature survey on greywate composition a set of model components (shown in Table 1) were chosen to represent major constituents in greywater.

Table 1: Components of the synthetic greywater solution

\begin{tabular}{|l|l|}
\hline Component & Representative of \\
\hline $\mathrm{NaCl}$ & Dissolved monovalent salt \\
\hline $\mathrm{NaHCO}_{3}$ & Natural buffer \\
\hline $\mathrm{Kaolin}$ & Inorganic particulate matter \\
\hline Cellulose & Organic particulate matter \\
\hline Humic acids & Dissolved organic matter \\
\hline $\mathrm{CaCl}$ & Dissolved multivalent salts \\
\hline Sodium dodecyl sulphate & Surfactants from shampoo and detergents \\
\hline
\end{tabular}

Humic acids (HAs) have been known for their fouling potential in membrane processes for quite some time. Previous studies have shown that membrane fouling by HAs is affected by many factors, including hydrodynamics and operating conditions, characteristics of the membranes and $\mathrm{HAs}$, solution $\mathrm{pH}$ and ionic strength [7-10].

Calcium is an important environmental component, and its complexation by humic materials has been long recognized [11]. Both are abundant in greywaters.

Other important components in greywater are surfactants. Surfactants have mainly been studied in the context of micellar enhanced UF, where a surfactant is added to the feed, which is later removed in form of micelles containing the pollutant $[12,13]$ and only few fouling studies are available $[14$, 15]. Archer et al., for example, found an increase in flux in the micellar critical region during nanofiltration (NF) of an anionic surfactant [14]. This indicates that surfactant concentration may play an important role in UF, both in terms of fouling as well as contaminant removal.

Hence, the main focus in this paper is on this influence of surfactant concentration (represented by sodium dodecyl sulphate (SDS) - a common ingredient used in shampoos and other haircare products) on fouling and retention.

\subsection{Ultrafiltration}

Submerged ultrafiltration membranes have recently attracted considerable interest in the water industry since they often require less energy than positive pressure driven configuration an comparatively little space $[16,17]$. Such advantage makes them a promising option for greywater recycling application.

Fouling and membrane performance are still a problem in UF processes and remain a key interest in current research. While most studies focus on single component fouling or large scale memb in enstor systems the influence of greywater constituents on fouling and retention and the feasibility of ultrafiltration systems in greywater recycling applications have to date not been addressed and are at the core of the current study.

\subsubsection{Calculations}

Parameters used to quantify the efficiency of UF, are the increase in TMP $(\Delta \mathrm{p})$ as an indicator for fouling, where $\mathrm{TMP}_{0}$ is the transmembrane pressure at the start of the experiment and $\mathrm{TMP}_{\mathrm{E}}$ is the transmembrane pressure at the end of the experiments

$$
\Delta \mathrm{p}=\mathrm{TMP}_{\mathrm{E}}-\mathrm{TMP}_{0}
$$


and solute rejection $(\mathrm{R})$ is calculated as indicated in $\mathrm{Eq}(2)$, where $\mathrm{c}_{\mathrm{F}}$ is the feed concentration at the start of the experiment and and $\mathrm{c}_{\mathrm{P}}$ the permeate concentration at the end of the experiment.

$$
R=100 \cdot\left(1-\frac{c_{P}}{c_{F}}\right)
$$

\section{Materials and Methods}

\subsection{Filtration Set up}

The experimental set up consists of a membrane module, a pump, and a pressure gauge as shown in Figure 1. The membrane is placed in a feed tank filled with 2.25 litres of feed solution. The system is equipped with a variable flow rate peristaltic pump which supplies the membrane with a negative pressure. The pressure (transmembrane pressure (TMP)) is continuous measured by pressure (TMP)) is continususly measured by constantly stirred using a magnetic stirrer.

\section{2. $\quad$ Membrane Module and Cleaning}

A ZeeWeed ${ }^{\circledR}$-1 (ZW-1) submerged hollow fibre ultrafiltration module supplied by Zenon Environmental was used in this study. This module operates in an "outside - in" configuration and has a nominal pore diameter of $0.04 \mu \mathrm{m}$, with an effective membrane surface area of $0.047 \mathrm{~m}^{2}$. The I membrane has a pure wat . The membrane is chloinne resistant and common hor Regular Bleach) was used for membrane cleaning at the end of each experiment. The active constituent is $3.5 \%$ Sodium Hypochlorite.

\subsection{Chemicals}

The chemicals used for preparing the synthetic greywater solution were sodium chloride, sodium hydroxyl carbonate calcium chloride and used were of analytical grade and used without further purification. Humic acids and analytical grade sodium dodecyl sulphate were purchased from Sigma Aldrich.

\subsection{Experimental protoco}

The synthetic greywater solution was prepared 16-18h before the experiment and stored at $4^{\circ} \mathrm{C}$ to allow equilibration of constituents. All experiments were conducted with a constant flow rate of 50 $\mathrm{mL} \cdot \mathrm{min}^{-1}$ and last approximately $5-6 \mathrm{~h}$. The TMP was recorded every $30 \mathrm{~min}$ as a fouling indicator, and feed and permeate samples were also taken for analysis at those intervals. Cleaning was conducted at the end of each experiment according to the following cleaning protocol. The conducted at perocol. The membrane was aerated for 15 min in the experimental solution. the cake layer. The membrane was then soaked in a $0.5 \mathrm{mg} . \mathrm{L}^{-1}$ surfactant solution, followed by bleach cleaning as indicated above.

\subsection{Analytical}

$\mathrm{UV}_{254}$ absorption, using a Shimadzu UV-Visible Spectrophotometer was measured as an indicator for HA concentration. Total organic carbon (TOC) was also measured using Shimadzu TOC-S instrument, but data was of little value to individual retention of specific organics given the contribution of all orgaics to the organic cabon content Cacium was anlysed using a Var Atomic Absorption Spectrometer. A "Micro $2 \mathrm{pH} / \mathrm{Ion}$ Meter" was used to determine $\mathrm{pH}$. $\mathrm{UV}_{254}$ an $\mathrm{pH}$ measurements were undertaken immediately, the rest of the samples were stored at $4{ }^{\circ} \mathrm{C}$ until time of calcium measurement.

\section{Results and Discussion}

4.1. Contribution of the model components to the fouling layer

Humic acids appear to strongly contribute to membrane fouling. Figure 2 shows the increase in TMP under different feed water conditions in three main categories of calcium concentration (i) absence of calcium (columns 3), (ii) $0.5 \mathrm{mM}$ calcium (column 1, $2 \& 4$ ), and (iii) $4 \mathrm{mM}$ calcium (column 5).

Without HAs and calcium (column 1) in the solution no fouling (or increase in suction pressure) occurs. It is possible that cellulose and kaoline particles in the solution form a porous cake layer, but pore size of the cake appears to be larger than the membrane pore size and has therefore no impact on TMP.

When the solution contains no particulate matter (kaoline and cellulose) but calcium and $\mathrm{HAs}$, little fouling occurs $(\Delta p=-2 \mathrm{kPa})$. In this case, fouling occurs possibly due to gel formation and adsorption of HAs onto the membrane surface and into pores [10]

Fouling is more severe when the feed solution contains both particulate matter and HAs (but no calcium; see column 3 in Figure 2) as particles form a cake layer on the membrane surface reinforced by the adsorption of HAs, resulting in a denser cake layer. This can be explained with an adsorption of the HAs on the particles and within the care pore structure. Further, the HAs are known to vary the structure of cakes formed.

When calcium is introduced into the solution a much stronger adsorption of HA results. HAs an calcium complexes form presumab enter the pores causing pore blockage resulting into a smaller pore size and a higher membrane resistance, which causes a strong increase in TMP $(\Delta \mathrm{p}=-12 \mathrm{kPa})$. This effect is confirmed by Saada et al. [18] who found calcium to enhance HAs adsorption onto kaolin and Hur [19], who found strong adsorption potential of HAs to kaolinite, which results in less free HAs molecules in the solution.

The particles contribute to fouling due to the formation of a cake layer on the surface, while HAs may cause fouling through adsorption onto the particle cake as well as the membrane surface. It has also been proven that calcium can act as a fouling facilitator via a bridging mechanism, enhancing HA adsorption and complexation with HAs and the membrane functional groups [20]. 
Oschmann, N. ; Nghiem, L.D. ; Schäfer, A. I. (2005) Fouling mechanisms of submerged ultrafiltration membranes in greywater recycling, Desalination, 179, 225-233 doi:10.1016/j.desal.2004.12.023

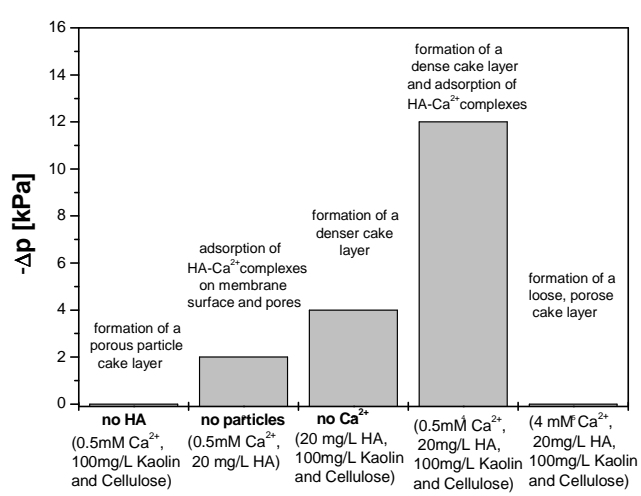

Figure 2: Membrane fouling under different experimental conditions (all experiments contained $10 \mathrm{mM} \mathrm{NaCl}$ and $1 \mathrm{mM} \mathrm{NaHCO}$

However, it is important to note that calcium only acts as a fouling facilitator in small concentrations around $0.5 \mathrm{mM}$. At a higher concentration, agglomerates of different structure and size were formed resulting in a more porous cake layer and hence less or no fouling (only one data point at $4 \mathrm{Ma}^{2+}$ is shown in Figure 2, ofher data Waite et al. [21] who found that relatively compact aggregates, resulting in a dense cake layer (high fouling) were obtained under reaction-limited aggregation conditions (low salt concentration). In contrast, more open particle assemblages were formed under diffusion-limited aggregation conditions (high salt condition), resulting in a porous cake layer (low fouling). It should be emphasized that the most fouling occurs in the calcium concentration range of tap water, which would also be the expected concentration range of greywater.

\subsection{Influence of SDS concentration on fouling and retention}

The influence of an anionic surfactant represented by sodium dodecyl sulphate (SDS) on membrane fouling expressed by increase in TMP and on permeate quality has been examined. One set of experiments was conducted with $0.5 \mathrm{mM}$ calcium and the second one with no calcium.

Experimental results indicate that SDS fouls the membrane in the absence of calcium, as shown in Figure 3, where TMP increases with an increase in SDS concentration up to a certain SDS concentration. The combination of particulate matter (kaolin and cellulose) and surfactants could cause stabilisation of the solid phase due to sorption of SDS onto the colloid surfaces and can possibly enhance fouling.

The levelling out at the higher SDS concentration is presumably caused due to micelle formation The levelling out resulting in less fritical micelle concentration $(\mathrm{cmc})$ for SDS in $2 \mathrm{mMN}$. Since the $\mathrm{NaCl}$ concentration in the experiments was $10 \mathrm{mM}$ and other salts and organics (known to lower the cmc concentration [22, 23]) were present in the solution as well, the cmc of SDS in this case is expected to be lower, presumably in the range between 1 and $2 \mathrm{mM}$. Acher found similar results during nanofiltration of SDS with an increase in fouling with SDS concentration, until a maximum value was reached close to the SDS cme [14].

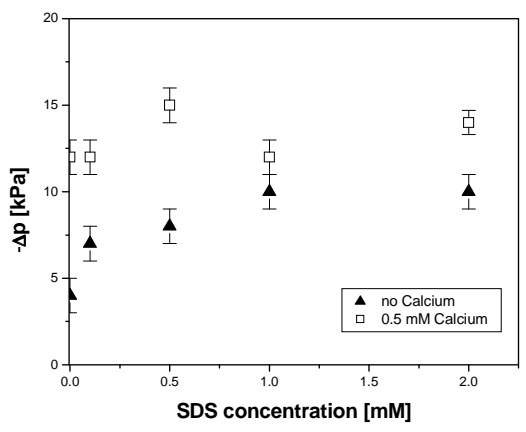

Figure 3: Membrane fouling at various SDS concentrations $\left(\mathrm{pH}\right.$ 7.6-8.8, $\mathrm{Ca}^{2+} \mathrm{o} / 0.5 \mathrm{mM}$, Kaolin and Cellulos 100m/L, $\mathrm{HA} 20 \mathrm{mg} / \mathrm{L}, \mathrm{NaCl} 10 \mathrm{mM}, \mathrm{NaHCO}_{3} 1 \mathrm{mM}$ )

In the presence of $0.5 \mathrm{mM}$ calcium in solution no actual influence of SDS concentration on fouling was found (Figure 3). Fouling in the presence of calcium is higher at all SDS concentrations compared to the experiments conducted in the absence of calcium, which suggest, that calcium is a compared to the experim

strong fouling facilitator.

Since SDS appears to enhance fouling it is surprising at first that SDS has no influence on fouling in the presence of calcium in the synthetic greywater solution. However, it is well known that interactions between ionic surfactants and oppositely charged ions like calcium ions are strong [23] It is hence hypothesized that SDS could affect fouling by inhibiting the role of calcium and HAs as fouling facilitators, resulting in less fouling, while at the same time causing fouling by adsorbing to particulate matter within the cake layer. At the experimental conditions the two opposite effects may cancel out each other.

The permeate $\mathrm{UV}_{254}$ absorption is increasing with increasing SDS concentration in the presence of calcium, with a steeper increase in the $\mathrm{cmc}$ region shown in Figure 4 . In the absence of calcium the permeate $\mathrm{UV}_{254}$ absorption drops when introducing SDS in the solution, then increasing with increasing SDS concentration until it decreases again in the cmc region. The permeate $\mathrm{UV}_{25}$ absorption is significantly higher in the absence of calcium, due to HA-calcium complexation, and enhanced adsorption and therefore retention $[11,18]$. The calcium concentration is decreasing with increasing SDS concentration, with the biggest decrease when introducing SDS in the solution and in the cmc region and a more moderate increase in the concentrations between 0.1 and $1 \mathrm{mM}$. The $\mathrm{UV}_{254}$ retention (Figure 5) shows a similar trend with UV retention slightly decreases as SDS concentration increases, while calcium retention increases with increasing SDS concentration.

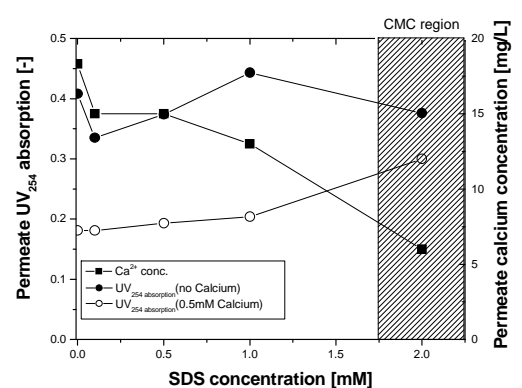

Figure 4: Permeate $\mathrm{UV}_{254}$ absorption and calcium concentration at different SDS concentration $\left(\mathrm{pH} 7.6-8.8, \mathrm{Ca}^{2+}\right.$ 0.5/0 $\mathrm{mM}, \mathrm{HA} 2 \mathrm{mg} / \mathrm{L}$, Kaolin and Cellulose $100 \mathrm{mg} / \mathrm{L}, \mathrm{NaCl} 10 \mathrm{mM}, \mathrm{NaHCO}_{3} 1 \mathrm{mM}$ ). Note that $0.5 \mathrm{mM} \mathrm{Ca}^{2+}$ correspond to $20 \mathrm{mg} / \mathrm{L}$ 
Oschmann, N. ; Nghiem, L.D. ; Schäfer, A. I. (2005) Fouling mechanisms of submerged ultrafiltration membranes in greywater recycling, Desalination, 179, 225-233

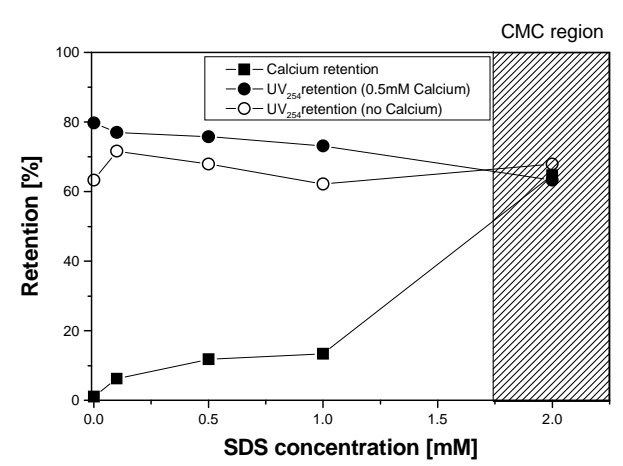

5: $\mathrm{UV}_{254}$ and calcium retention at different SDS concentrations ( $\mathrm{pH} 7.6-8.8, \mathrm{Ca}^{2+} 0.5 / 0 \mathrm{mM}, \mathrm{HA} 20 \mathrm{mg} / \mathrm{L}$ Kaolin and Cellulose $100 \mathrm{mg} / \mathrm{L}, \mathrm{NaCl} 10 \mathrm{mM}, \mathrm{NaHCO}_{3} 1 \mathrm{mM}$ )

The decrease in $\mathrm{UV}_{254}$ retention can be explained by the competition between HAs and SDS for the absorptive sites available on particles. SDS strongly absorbs onto kaolin [24] and therefore averts HA adsorption, which stays in solution and is therefore not retained (see also Figure 6). In the cmc region (absence of calcium) SDS forms micelles and frees the adsorption sites for HA resulting in higher HA retention.

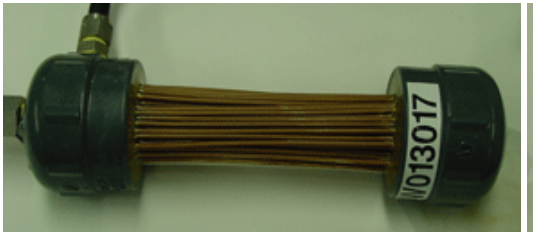

no SDS

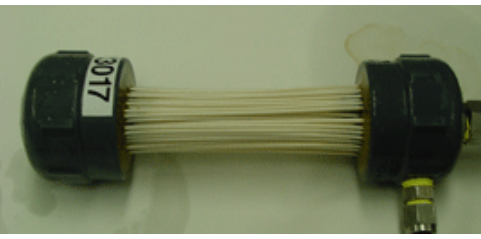

$1 \mathrm{mM}$ SDS

\section{Figure 6: Menbrane after an experiment without SDS and with 1mM SDS}

The electrostatic repulsion is decreased when introducing calcium in the solution. Calcium is also known to interact with SDS, which results in less calcium-humic acid interactions. This could also explain the further increase in the cmc region. Micelle formation results in more free adsorption sites, but binds calcium, which could result in overall less HAs retention. The increasing calcium permeate concentration with SDS concentration results confirm this hypothesis. Calcium retention (Figure 5) is increasing with increasing SDS concentration with a high (more than 60\%) retention in the $\mathrm{cmc}$ region. The surfactant micelles have a high electrical potential that can cause the calcium ions to bind or sorb on the micelles due to electrostatic attraction (see Figure 7). The membrane then retains the micelles containing the calcium. This mechanism is well under stood from the process known as micellar-enhanced ultrafiltration [12-14] but would occur naturally in greywater filtration.

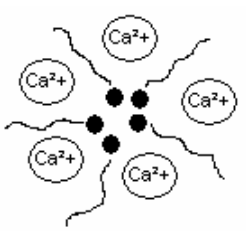

Figure 7: Calcium ions binding to SDS micelles

\section{Conclusions}

The role of surfactant sodium dodecyl sulphate (SDS) and other model solutes in the fouling of submerged ultrafiltration membranes in a greywater recycling application was investigated. The extend of fouling is highly influenced by the composition of the feed, where solution chemistry and solute-solute interactions play an important role in how the fouling layer associates with the solute-solute interactions play an important role in how the fouling layer associates with the
membrane surface. A major fouling factor is the combination of low calcium ion concentration and humic acids (HAs), which could be a concern seeing that the most fouling was observed for tap water calcium concentrations $(0.5 \mathrm{mM})$. It can also be concluded from the above experiments that SDS can cause fouling through particle stabilisation and strongly interact with calcium enhancing calcium retention especially in the cmc region. SDS competes with HAs for adsorption sites resulting in less HA retention. If ultrafiltration processes in greywater recycling application are to be economically feasible then fouling and cleaning need to be considered and system and operation parameters adjusted accordingly and further work will focus on further understanding of such mechanisms and their impact on water quality.

\section{Acknowledgements}

The authors would like to acknowledge Gosford City Council for providing the funding for the project, Deutscher Akademischer Austausch Dienst (DAAD) for providing a scholarship for Nadine Oschmann and Zenon Environmental for providing the UF membrane. Joanne George is acknowledged for extensive technical and analytical support in the Environmental Engineering Laboratory at UoW.

\section{References}

1. Al-Jayyousi, O.R., Greywater reuse: towards sustainable water management. Desalination, 2003. 156(1-3): p. 181-192.

2. Nolde, E., Greywater reuse systems for toilet flushing in multi-storey buildings - over ten years experience in Berlin. Urban Water, 2000. 1(4): p. 275-284.

3. Christova-Boal, D., R.E. Eden, and S. McFarlane, An investigation into greywater reuse for urban residential properties. Desalination, 1996. 106(1-3): p. 391-397.

4. Jefferson, B., A. Palmer, P. Jeffrey, R. Stuetz, and S. Judd, Grey water characterisation and its impact on the selectilon and operation of technologies for urban rense. Water Science \& Technology, 2004 50(2): p. 157-164.

5. Eriksson, E., K. Auffarth, M. Henze, and A. Ledin, Characteristics of grey wastewater. Urban Water, 2002. 4(1): p. 85-104

6. Metcalf \& Eddy and G. Tchobanoglous, Wastewater Engineering Treatment Disposal Reuse. 1991: Mc Graw-Hill Inc.

7. Kulovaara, M., S. Metsamuuronen, and M. Nystrom, Effects of aquatic humic substances on a hydrophobic ultrafiltration membrane. Chemosphere, 1999. 38(15): p. 3485-3496.

8. Jucker, C. and M.M. Clark, Adsorption of aquatic humic substances on hydrophobic ultrafiltration membranes. Journal of Membrane Science, 1994. 97: p. 37-52. 
Braghetta, A., F.A. Digiano, and W.P. Ball, Nanofiltraion of natural organic matter: $p H$ and ionic strength effects. Journal of Environmental Engineering, 1997. 123(7): p. 628-641.

10. Schäfer, A.I., Natural Organics Removal using Membranes: Principles, Performance and Cost. 2001: Technomic Publishing Company.

11. Clark, M.M. and P. Lucas, Diffusion and partitioning of humic acid in a porous ultrafiltration membrane. Journal of Membrane Science, 1998. 143(1-2): p. 13-25.

12. Baek, K., B.-K. Kim, and J.-W. Yang, Application of micellar enhanced ultrafiltration for nutrients removal. Desalination, 2003. 156(1-3): p. 137-144.

13. Baek, K., H.-H. Lee, and J.-W. Yang, Micellar-enhanced ultrafiltration for simultaneous removal of ferricyanide and nitrate. Desalination, 2003. 158(1-3): p. 157-166.

14. Archer, A.C., A.M. Mendes, and R.A.R. Boaventura, Separation of an anionic surfactant by nanofiltration. Environmental Science \& Technology, 1999. 33(16): p. 2758-2764.

15. Childress, A.E. and M. Elimelech, Relating nanofiltration membrane performance to membrane charge (electrokinetic) characteristics. Environmental Science and Technology, 2000. 34(17): p. 3710-3716.

16. Wintgens, T., J. Rosen, T. Melin, C. Brepols, K. Drensla, and N. Engelhardt, Modelling of a membran bioreactor system for Science, 2003. 216(1-2): p. 55-65.

17. Rosenberger, S., U. Kruger, R. Witzig, W. Manz, U. Szewzyk, and M. Kraume, Performance of a bioreactor with submerged membranes for aerobic treatment of municipal waste water. Water Research, 2002. 36(2): p. 413-420.

18. Saada, A., D. Breeze, C. Crouzet, S. Cornu, and P. Baranger, Adsorption of arsenic (V) on kaolinite and on kaolinite-humic acid complexes: Role of humic acid nitrogen groups. Chemosphere, 2003. 51(8): p. 757-763.

19. Hur, J. and M.A. Schlautman, Molecular weight fractionation of humic substances by adsorption onto minerals. Journal of Colloid and Interface Science, 2003. 264(2): p. 313321.

20. Qilin Li and M. Elimelech, Organic Fouling and Chemical Cleaning of Nanofiltration Membranes: Measurements and Mechanisms. Environmental Science \& Technology, 2004. 38(17): p. 4683-4693.

21. Waite, T.D., A.I. Schäfer, A.G. Fane, and A. Heuer, Colloidal Fouling of Ultrafiltration Membranes: Impact of Aggregate Structure and Size. Journal of Colloid and Interface Science, 1999. 212(2): p. 264-274.

22. Hiemenz, P.C. and R. Rajagopalan, Principles of Colloid and Surface Chemistry. 3rd ed. 1997: Marcel Dekker Inc.

23. Koopal, L.K., T.P. Goloub, and T.A. Davis, Binding of ionic surfactants to purified humic acid. Journal of Colloid and Interface Science, 2004. 275(2): p. 360-367.

24. Chang, Y.J. and M.M. Benjamin, Iron oxide adsorption and UF to remove NOM and control fouling. Journal American Water Works Association, 1996. 88(12): p. 74-88. 